\title{
PERILAKU SOSIAL PEKERJA SEKS KOMERSIAL DI KOTA SURAKARTA
}

\author{
Defi Putri Widyawati ${ }^{1}$, Sudarsana ${ }^{2}$ \\ Program Studi Sosiologi Fakultas Ilmu Sosial dan Politik \\ Universitas Sebelas Maret Surakarta Indonesia \\ Email$^{1}$ : defiputriw@gmail.com,Email²: sudarsana@staff.uns.ac.id
}

\begin{abstract}
This study was designed to describe the social conversations of callous women in Surakarta. As well as describing the factors that cause women to behave as callous women in Surakarta. This research is a case study using qualitative research. The subjects of the study were prostitutes, adolescent women as college students and single citizens in the Surakarta area as informants. Data collection using the method of observation and interviews in. Researchers are the main research instruments that provide observation guidelines and interview guidelines. Data analysis techniques used are data display, data reduction, and conclusions are drawn. Triangulation used is source triangulation. The results showed that the average informant who was a prostitute woman was still a girl. Regarding the work of the average informant has a main job Although small businesses, because the status as a prostitute woman calls only side. As parents, the average daughter does not know if she has worked as a prostitute. Informant's motivation in working as a prostitute woman on average wants to get more income to meet her needs. In choosing a job as a prostitute woman the average call informant has never had a plan towards being a prostitute woman, and never the status of prostitute women looking for work goals. Actions taken at work, as a tuna woman, and this information is only doubled, within 2 hours can be done to meet their needs for several months. In conducting discussions with coworkers in supermarkets and colleagues in entertainment venues, information on average is not difficult, they can work together, help each other, and foster good relations with one another. The average informant who has fear of the dangers of HIV that befell him. Make them always check their female health to the doctor. The thought of quitting work as immoral women asks all of them to stop because they also understand that this is not good to continue until old age. Factors that can cause informants to plunge into the world of prostitutes are high economic factors.
\end{abstract}

Keywords: Social behavior, Prostitute Woman.

Abstrak: Penelitian ini bertujuan untuk mendeskripsikan perilaku sosial wanita tuna susila Panggilan di Surakarta. Serta mendeskripsikan faktor-faktor yang menyebabkan wanita berperilaku sebagai wanita tuna susila panggilan di Surakarta. Penelitian ini merupakan penelitian studi kasus dengan menggunakan pendekatan kualitatif. Subyek penelitian adalah wanita tuna susila, wanita remaja sebagai mahasiswi dan warga berstatus lajang di wilayah Surakarta sebagai informan. Pengumpulan data menggunakan metode observasi dan wawancara mendalam. Peneliti merupakan instrumen utama penelitian dengan dibantu pedoman observasi dan pedoman wawancara. Teknik analisis data yang digunakan adalah display data, reduksi data, dan penarikan kesimpulan. Triangulasi yang digunakan adalah triangulasi sumber. Hasil penelitian menunjukkan bahwa rata-rata informan yang berstatus sebagai wanita tuna susila panggilan masih gadis. Mengenai pekerjaan rata-rata informan mempunyai kerjaan utama walaupun usaha kecil-kecilan, karena status sebagai wanita tuna susila panggilan hanya sampingan. Sebagai orang tua, rata-rata anak gadisnya tidak mengetahuinya kalau anaknya bekerja juga sebagai wanita tuna susila panggilan. Motivasi informan dalam bekerja sebagai wanita tuna susila panggilan rata-rata ingin mempunyai 
pendapatan yang lebih guna mencukupi kebutuhannya. Dalam memilih pekerjaan sebagai wanita tuna susila panggilan rata-rata informan tidak pernah mempunyai rencana kearah sebagai wanita tuna susila, dan tidak pernah bahwa status wanita tuna susila panggilan sebagai tujuan pekerjaan utamanya. Tindakan yang dilakukan dalam menjalani pekerjaannya sebagai wanita tuna susila panggilan tersebut rata-rata informanhanya 2 kali salam seminggu, dalam menjalani 2 kali seminggu biasanya bisa buat mencukupi kebutuhannya selama setengah bulan. Dalam melakukan pendekatan dengan teman kerja di swalayan maupun teman kerja di tempat hiburan rata-rata informan tidak mengalami kesulitan, mereka bisa selalu bekerja sama saling membantu dan saling membina hubungan baik. Rata-rata informan mempunyai rasa takut akan bahaya HIV yang menimpanya. Sehingga mereka selalu memeriksakan kesehatan kewanitaannya ke dokter. Pemikiran untuk berhenti dari pekerjaan sebagai wanita tuna susila panggilan mereka semua mempunyai niat untuk berhenti karena juga menyadari bahwa hal tersebut tidak baik untuk diteruskan sampai hari tua. Faktor-faktor yang dapat menyebabkan informan terjun ke dunia wanita tuna susila panggilan tersebut adalah faktor ekonomi yang cukup tinggi.

Kata Kunci: Perilaku sosial, Wanita Tuna Susila.

\section{PENDAHULUAN}

Wanita PKS (Pekerja Seks Komersial) di masyarakat kerap menjadi bahan perbincangan bagi ibu -ibu rumah tangga karena menurut pendapat ibu ibu rumah tangga wanita tuna susila sebagai perusak rumah tangga orang dan identik dengan sebutan wanita kupu-kupu malam. Wanita PKS (Pekerja Seks Komersial) dianggap sebagai sampah masyarakat bagi penilaian masyarakat secara umum. Banyak yang mengatakan bahwa wanita tuna susila menjadi hal yang sangat mengganggu masyarakat sekitar lebih - lebih dalam lingkup perkampungan maupun perumahan. Di dalam perkampungan tidak sedikit pula ada wanita PKS (Pekerja Seks Komersial) yang berada atau tinggal didalamnya tanpa diketahui oleh lingkungan setempat. Hal ini seperti yang terjadi di suatu tempat tertentu di kecamatan Njebres pernah penulis ketahui bahwa ada wanita tuna susila yang berdomosili di situ yang menempati di tempat kos kosan. Tempat kos kosan sering digunakan oleh wanita PKS (Pekerja Seks Komersial) berdomisili karena begitu mudah tempat dijadikan sebagai tempat tinggal agar perilakunya tidak diketahui oleh keluarga besarnya maupun teman terdekatnya. Keluarga pada umumnya tidak mengetahui apabila bahwa seorang anaknya menjadi wanita tuna susila karena tidak dalam satu atap hidupnya. Biasanya seorang anak remaja yang menjadi wanita PKS (Pekerja Seks Komersial) tidak hanya sebagai tuntutan kehidupan keluarga namun ada yang sudah sebagai pilihannya agar bisa mendapatkan segala sesuatu dengan mudahnya untuk mencukupi kebutuhannya. Lebih-lebih remaja yang berstatus mahasiswi tidak mau ketinggalan dengan penampilan teman-temannya yang kaya dan hidup serba mewah.

Lain halnya bagi seorang wanita PKS (Pekerja Seks Komersial) yang berstatus janda pada umumnya mereka akan adanya tuntutan ekonomi yang menimpanya karena ditinggalkan oleh suaminya sehingga mereka rela mengorbankan dirinya demi untuk mencukupi kebutuhannya. Kebutuhan rumah tangga yang begitu tinggi untuk dipenuhinya terutama kebutuhan sekolah anaknya, maupun kebutuhan sehari-hari harus dipenuhinya mau tidak mau harus tetap mencukupinya, hal inilah yang mendorong bagi ibu ibu muda yang berstatus wanita PKS (Pekerja Seks Komersial). Jadi pada umumnya ibu muda yang berstaus wanita PKS (Pekerja Seks Komersial) kebanyakan karena adanya tuntutan ekonomi yang mendasari 
terjun ke dunia terlarang tersebut. Hal ini seperti yang diutarakan oleh Sularmi (Ibu muda yang menempati kos kosan di wilayah Njebres) ia sering keluar malem untuk bekerja sampai pagi baru pulang. Baru dalam sebulan sekali pulang ke keluarga besarnya untuk memberikan uang kepada anaknya yang diasuh oleh neneknya di kampung halamannya.

Dalam kurun waktu yang berbeda penulis, pernah menemui dalam suatu tempat tertentu di sebuah kafe bertemu dengan seorang mahasiswi yang selain sebagai penyanyi kafe juga sebagai wanita PKS (Pekerja Seks Komersial), ia mengatakan bahwa setelah kegiatan menyanyi tidak jarang ada om om yang meminta untuk ditemani ngobrol sebentar yang berlanjut ke tempat penginapan dimana yang sebelumnya ada perjanjian perjanjian tertentu didalamnya sebelum mendatangi ke penginapan. Kebiasaan kebiasaan seperti inilah yang sering digunakan oleh wanita PKS (Pekerja Seks Komersial) yang juga sebagai penyanyi kafe. Disamping menyalurkan hobinya menyanyi tetapi juga mendapatkan hasil yang lebih karena dapat dicapainya hasil yang lumayan dengan mudah dan juga kesenangan. Kesenangan yang salah kaprah inilah kadang yang kurang disadari oleh kaum remaja khususnya anak kampus. Adanya keinginan untuk berpenampilan yang tidak mau ketinggalan dengan teman lainnya, sehingga kadang bisa menghalalkan segala cara demi mendapatkan segalanya dengan mudah yang pada akhirnya mengalami kehamilan di luar nikah. Kehamilan yang tidak diinginkannya inilah yang menyebabkan mereka melakukan prostitusi karena kehadiran bayi tidak diinginkannya apalagi keluarganya. Keluarga yang selalu mengawasi perkembangan anaknya walaupun di luar rumah pasti tidak akan terjadi hal hal yang tidak diinginkannya, seperti halnya yang menimpa pada anak anak remaja di atas. Namun sebaliknya anak anak remaja yang menjadi kupu-kupu malam tersebut biasanya rata rata lahir dari keluarga yang broken home karena tanpa ada pengawasan oleh kedua orang tuanya. Sebagai orang tua sudah semestinya harus mengadakan pengawasan kepada anaknya bilamana berada di luar rumah lebih lebih apabila hidup dalam suatu kos kosan dengan dalih tempat kuliah jauh dari rumah sehingga bertempat tinggal pada sebuah tempat kos tertentu. Perilaku anak perlu diawasi lebih lebih anak remaja bila berada di luar rumah agar anak tidak terjerumus pada teman yang berstatus sebagai kupu kupu malam. Karena faktor lingkungan sangat mudah mempengaruhinya dalam pergaulan maupun kehidupannya dalam berperilaku. Lingkungan yang nyaman aman akan menyebabkan kehidupan yang menjadikan lebih baik namun sebaliknya lingkungan yang kurang baik akan menimbulkan hal-hal yang kurang baik pula, hal ini seperti yang terjadi pada anak-anak kos yang terlahir dari keluarga broken home.

Berdasarkan survai penulis, yang kami temui perilaku sosial remaja pada umumnya sangat mudah terpengaruhi oleh lingkungannya, hal ini seperti yang terjadi pada Ernawati remaja yang baru saja lulus SMA beliau sering pulang malam hari bahkan sampai jam 24.00 malam, setelah ditanya oleh orang tuanya kenapa baru pulang dan darimana ternyata jawabnya dari Solo Square yang berlanjut nongkrong dengan teman temannya di suatu tempat makan dan minum karena teman teman dekatnya pada berada di situ sehingga ikut didalamnya. Nah, faktor-faktor seperti inilah yang perlu dilakukan pengawasan oleh orang tua yang mempunyai keluarga baik baik dan utuh agar anaknya tidak terjerumus pada perilaku sosial yang tidak bermanfaat bahkan menjadi aib dalam sebuah keluarga. Lantas dalam penulisan ini, perilaku sosial yang bagaimanakah yang dikategorikan perilaku wanita PKS (Pekerja Seks Komersial) ? Karena belum bisa diketahui secara pasti, macam wanita seperti apa yang dapat dikatakan wanita PKS (Pekerja Seks Komersial). Wanita PKS (Pekerja Seks Komersial) identik dengan wanita yang bisa diajak kencan oleh seseorang khususnya laki-laki hidung belang yang berlanjut mendapatkan imbalan bilamana mau diajak kencan ke suatu tempat tertentu. Tempat yang menjadikan seorang wanita tersebut dengan laki-laki hidung belang dapat memuaskannya walaupun misalnya hanya sekedar ngobrol dan 
makan atau minum saja. Tempat ini biasanya seperti yang terdapat pada tempat tempat hiburan tertentu misalnya di klub klub karaokenan ataupun yang berkedok salon kecantikan yang menawarkan pijat kebugaran. Namun, di sisi lain tempat tempat hiburan seperti di tempat karaokenan tidak bisa dikatakan sebagai tempat kencan secara mutlak bagi wanita PKS (Pekerja Seks Komersial) karena tempat hiburan karaokenan adalah milik masyarakat umum yang tidak sedikit pula digunakan untuk menyalurkan hobinya sebagai kegiatan menyanyi dan berkumpulan kalangan anak muda. Perilaku sosial yang beraneka ragam inilah yang dilakukan oleh masyarakat umum pada umumnya dan perilaku sosial yang menyimpang yang dilakukan oleh sebagian masyarakat kecil pada khususnya yaitu anak wanita remaja yang mau diajak berkencan oleh kaum laki laki yang berduit atau beruang. Uang kerap kali menjadi ketertarikan bagi kaum remaja wanita yang suka berbelanja dan hidup dalam kemewahan dimana keluarganya tidak bisa mencukupi kebutuhannya dalam berinteraksi dengan teman sebayanya dalam hal berpenampilan. Penampilan yang bersifat mewah dan bergengsi inilah yang menjadikan kaum remaja wanita mempunyai kebiasaan buruk bagi dirinya yang sebelumnya tanpa mereka sadari.

\section{METODE PENELITIAN}

Dalam penelitian ini, peneliti menggunakan metode penelitian kualitatif. Dimana penelitian yang yang bermaksud untuk memahami fenomena tentang apa yang dialami oleh subjek penelitian misalnya perilaku, persepsi, motivasi, tindakan, dan lain-lain, secara holistik, dan dengan cara deskripsi dalam bentuk kata-kata dan bahasa, pada suatu konteks khusus alamiah dan dengan memanfaatkan berbagai metode alamiah (Moleong, 2010:6). Dalam penelitian ini ditekankan pada penelitian kualitatif deskriptif. Dimana data yang dikumpulkan adalah berupa kata-kata, gambar, dan bukan angka-angka (Moleong, 2010:11). Adapun tujuan dari penelitian deskriptif kualitatif adalah untuk membuat pencandraan secara sistematis, faktual, dan akurat mengenai fakta dan sifat populasi atau daerah tertentu.

\section{HASIL PENELITIAN DAN PEMBAHASAN}

Masalah sosial menyangkut nilai-nilai sosial dan moral. Masalah tersebut merupakan persoalan karena menyangkut tata kelakuan immoral, berlawanan dengan hukum dan bersifat merusak. Oleh sebab itu, masalah-masalah sosial tak akan mungkin ditelaah tanpa mempertimbangkan ukuran-ukuran masyarakat mengenai apa yang dianggap baik dan apa yang dianggap buruk. Sosiologi menyangkut teori yang hanya dalam batas tertentu menyangkut nilai-nilai sosial dan moral, yang terpokok adalah aspek ilmiahnya. (Robert A. Nisbet dalam Soerjono Soekanto, 2013; 313)

Banyak studi yang telah dilakukan oleh para ahli untuk mendapatkan jawaban mengenai faktor yang mempengaruhi perempuan menjadi pelacur. Weisberg (Koentjoro, 2004:53-55) menemukan adanya tiga motif utama yang menyebabkan perempuan memasuki dunia pelacuran, yaitu :

a Motif psikoanalisis menekankan aspek neurosis pelacuran, seperti bertindak sebagaimana konflik Oedipus dan kebutuhan untuk menentang standar orang tua dan sosial.

b Motif ekonomi secara sadar menjadi faktor yang memotivasi. Motif ekonomi ini yang dimaksud adalah uang.

c Motivasi situasional, termasuk di dalamnya penyalahgunaan kekuasaan orang tua, penyalahgunaan fisik, merendahkan dan buruknya hubungan dengan orang tua. Weisberg juga meletakkan pengalaman di awal kehidupan, seperti pengalaman seksual diri dan peristiwa traumatic sebagai bagian dari motivasi situasional. Dalam 
banyak kasus ditemukan bahwa perempuan menjadi pelacur karena telah kehilangan keperawanan sebelum menikah atau hamil di luar nikah.

Menurut Greenwald (Koentjoro, 2004:53) mengemukakan bahwa"faktor yang melatarbelakangi seseorang untuk menjadi pelacur adalah faktor kepribadian." Ketidakbahagiaan akibat pola hidup, pemenuhan kebutuhan untuk membuktikan tubuh yang menarik melalui kontak seksual dengan bermacam-macam pria, dan sejarah perkembangan cenderung mempengaruhi perempuan menjadi pelacur.

\section{Perilaku Sosial Menyimpang}

Perilaku Sosial yang menyimpang tidak lain adalah perilaku yang dapat dikategorikan seperti halnya tentang pelacuran. Sedangkan hal-hal yang dimasukkan dalam kategori pelacuran, menurut Kartini Kartono (2015 : 217-218) ini antara lain ialah :

a Pergundikan: pemeliharaan bini tidak resmi, bini gelap atau perempuan piaraan. Mereka hidup sebagai suami isteri, namun tanpa ikatan perkawinan.

b Tante girang atau loose married woman: yaitu wanita yang sudah kawin, namun tetap melakukan hubungan erotik dan seks dengan laki-laki lain baik secara iseng untuk mengisi waktu kosong, bersenang-senang just for fun dan mendaoatkan pengalamanpengalaman seks lain, maupun secara intensional untuk mendapatkan penghasilan.

c Gadis-gadis panggilan: ialah gadis-gadis dan wanit-wanita biasa yang menyediakan diri untuk dipanggil dan dipekerjakan sebagai prostitue, melalui saluran-saluran tertentu.

d Gadis-gadis bar atau B-girls: yaitu gadis-gadis yang bekerja sebagai pelayan-pelayan bar sekaligus bersedia memberikan pelayanan seks kepada para pengnjung.

e Gadis-gadis juvenile delinguent: yaitu gadis-gadis muda dan jahat,yang didorong oleh ketidakmatangan emosinya dan retardasi/ keterbelakangan inteleknya, menjadi sangat pasif dan sugestibel sekali.

f Gadis-gadis binal atau free girls; di Bandung mereka menyebut diri sebagai "bagong lieur" (babi hutan yang mabuk).

g Gadis-gadis taxi yaitu wanita=wanita dan gadis-gadis panggilan yang ditawarkan dibawa ke tempat 'plesiran' dengan taksi= taksi atau becak.

Hal-hal tersebut di atas menjelaskan bahwa adanya perilaku sosial yang terjadi antara perempuan dan laki-laki untuk saling memuaskan kebutuhannya.

\section{WTS (Wanita Tuna Susila)}

Wanita tuna susila panggilan dapat dikatakan sebagai wanita yang tidak mempunyai etika atau norma. Dimana seperti yang disampaikan oleh Koentjoro (2004: 27) mengatakan bahwa wanita tuna susila (WTS) sabagai perempuan yang tidak menuruti aturan susila yang berlaku di masyarakat dan dianggap tidak memiliki adap dan sopan santun dalam berhubungan seks. Bahkan ada yang menyebutnya sebagai pelacur, hal ini seperti yang di sampaikan oleh Perkins dan Bennet dalam Koentjoro (2004: 30), mengatakan bahwa pelacuran sebagai transaksi bisnis yang disepakati oleh pihak yang terlibat sebagai sesuatu yang bersifat kontrak jangka pendek yang memungkinkan satu orang atau lebih mendapatkan kepuasan seks dengan metode yang beraneka ragam. Berdasarkan pembahasan di atas, berkaitan dengan perilaku sosial wanita tuna susila panggilan di wilayah kota Surakarta bahwa penulis telah mendapatkan empat narasumber yang dapat dijelaskan guna mengetahui hal yang berkaitan dengan perilaku wanita yang menyimpang, dan dua orang sebagai pendukung kegiatan WTS. 


\section{KESIMPULAN}

Berdasarkan pembahasan permasalahan di atas, mengenai perilaku social wanita PSK (Pekerja Seks Komersial) di wilayah kota Surakarta dapat ditarik kesimpulan sebagai berikut:

1. Rata-rata informan yang berstatus sebagai wanita PKS (Pekerja Seks Komersial) masih gadis, hanya satu yang berstatuskan janda dan ketiga gadis tersebut masih kuliahsemua.

2. Mengenai pekerjaan rata-rata informan mempunyai kerjaan utama walaupun usaha kecil-kecilan, karena status sebagai PKS (Pekerja Seks Komersial) panggilan hanya sebagai pekerjaan sampingan.

3. Sebagai orang tua, rata-rata anak gadisnya tidak mengetahuinya kalau anaknya bekerja juga sebagai PKS (Pekerja Seks Komersial)

4. Motivasi informan dalam bekerja sebagai PKS (Pekerja Seks Komersial) rata-rata ingin mempunyai pendapatan yang lebih guna mencukupi kebutuhannya sehari-hari yang tinggi.

5. Dalam memilih pekerjaan sebagai PKS (Pekerja Seks Komersial) rata-rata informan tidak pernah mempunyai rencana kearah sebagai PKS (Pekerja Seks Komersial), dan tidak pernah bahwa status PKS (Pekerja Seks Komersial) sebagai tujuan pekerjaan utamanya.

6. Tindakan yang dilakukan dalam menjalani pekerjaannya sebagai WTS (wanita tuna susila ) panggilan tersebut rata-rata informan hanya 2 kali salam seminggu, dalam menjalani 2 kali seminggu biasanya bisa buat mencukupi kebutuhannya selama setengah bulan, pekerjaan sebagai WTS nya tidak dijalaninya setiap hari karena mempunyai pekerjaan utama di sebuah toko swalayan area Surakarta juga.

7. Dalam melakukan pendekatan baik dengan teman kerja di swalayan maupun teman kerja di tempat hiburan rata-rata informan tidak mengalami kesulitan, mereka bisa selalu bekerjasama saling membantu dan saling membina hubungan baik.

8. Rata-rata informan mempunyai rasa takut akan bahaya HIV yang menimpanya. Sehingga mereka selalu memeriksakan kesehatan kewanitaannya kedokter.

9. Pemikiran untuk berhenti dari pekerjaan sebagai WTS (wanita tuna susila ) panggilan mereka semua mempunya I niat untuk berhenti karena juga menyadari bahwa hal ter sebut tidak baik untuk diteruskan sampai hari tua.

10. Faktor-faktor yang dapat menyebabkan informan terjun kedunia WTS (wanita tuna susila) panggilan tersebut adalah factor ekonomi yaitu tuntutan kebutuhan kehidupan yang cukup tinggi.

\section{DAFTAR PUSTAKA}

Abdulsyani. (2015). Sosiologi: Skematika, Teori dn Terapan. Jakarta: Bumi Aksara. Faisal, Sanapiah. (2008). Format-format Penelitian Sosial. Jakarta: Rajawali Pers. Rathus, S. (1983). Human Sexuality in A World of Diversity.Allyn and Bacon, Massachusets. Margono. (2005). Metode Penelitian Pendidikan. Jakarta: Rineka Cipta Kartini Kartono. (2015). Patologi Sosial. Jakarta: Raja Grafindo Persada. Koentjoro. (2004). On the Spot: Tutur Dari Sarang Pelacur. Yogyakarta: Tinta. Koentjaraningrat,(1997) Metode Penelitian Masyarakat (Jakarta:PT Gramedia Pustaka. Sarwono, S.W. (2000), Teori-teori Psikologi Sosial. Jakarta: Raja Grafindo Persada. Soerjono Soekanto. 2013. Sosiologi Suatu Pengantar; edisi revisi . Jakarta: Rawali Press Sugiyono (2008). Memahami Penelitian Kualitatif. Bandung: Alfabeta. 